\title{
Design, Fabrication, and Performance Evaluation of a Hammer Mill for Small-Scale Corn Milling Operation
}

\author{
Erickson N. Dominguez \\ Instructor, Department of Agricultural and Biosystems Engineering, College of Engineering, Benguet State University, \\ Philippines
}

\begin{abstract}
Particle size reduction is an operation done to corn (Zea mays) to command higher price marketability of the product. Smaller particle size also improves the digestibility of nutrients making feed energy conversion efficient. The majority of the available corn mill designs in the Philippine market are for the village and industrial level operations that are high in price and capacity. The aim of this study was to develop a financially feasible hammer mill for small-scale corn milling operation. The study also considered the separation of the fine corn grits and the coarse corn grits to provide an option in the utilization as feed to a different age of animals. The designed and fabricated hammer mill comprised of the milling chamber, grits outlet, suction fan, cyclone separator, prime mover, and frame. The hammer mill was evaluated at different operating tip speeds of $28 \mathrm{~m} / \mathrm{s}, 22$ $\mathrm{m} / \mathrm{s}, 19 \mathrm{~m} / \mathrm{s}$, and $14 \mathrm{~m} / \mathrm{s}$ using parameters such as the milling capacity, milling efficiency, particle size output, and electrical energy consumptions. The result of the evaluation showed that $28 \mathrm{~m} / \mathrm{s}$ results in a "medium" corn grits collected at the grits outlet. "Coarse" milled corn was observed at the operating speed of $22 \mathrm{~m} / \mathrm{s}, 19 \mathrm{~m} / \mathrm{s}$, and 14 $\mathrm{m} / \mathrm{s}$ at the grits outlet. Collected milled corn at the cyclone separator has a "fine" classification. Simple cost analysis revealed that the machine has a break-even point of 4,048 $\mathrm{kg} / \mathrm{yr}$ and a payback period of 26 days at 2 Php custom rate.
\end{abstract}

Keywords: corn, hammer mill, size reduction, small-scale machine, machinery design.

\section{INTRODUCTION}

Corn (Zea mays) is one of the major commodity used as a feed ingredient for animal consumption. According to the International Grains Council (IGC), total corn (maize) production in the Philippines was 6.8 million tons for 2010 (Lyddon, 2011). It has different sizes available in the market at different prices ranging from whole corn, which has a lower price, to smaller corn grits, which has a higher price. These imply that raw products in agriculture are cheaper compared to processed products by size reduction.
Particle size reduction is a process to reduce the size of a feed product to increase the efficiency of feed utilization. Also, particle size reduction influences the uniformity of feed mixed delivered to the animal. It also increases the area of the product being exposed to heat, moisture, and enzymes; increasing palatability (Mississippi State University Extension, 2010). This process is also done to prepare for operations like mixing, pelleting and extrusion, and handling and conveying.

Hammer mill is one of the machines used in size reduction. Hammer mills reduce particle size by breaking due to the impact of the hammers, shearing by the edge of the hammers and screen, and collision among the product and in between the product and machine. The impact is the primary force to reduce particle size in a hammer mill. The increase in the chance of collision between the hammer and the target decreases the time of milling. The area of the perforation of the screen in the hammer mill determines the size of the output product. Also, Koch (2002) added that hammer-tip speed, hammer design and spacing, and the use of air-assist such as suction fan and cyclone separator affect the size output of the hammer mill.

Whole corn is sometimes too large to be consumed by animals' ata young age. Size reduction of grains adds value to the product, especially with the consistency of the size. However, small-scale farm operators do not get these added values because they do not process their produce themselves. Available designs of a corn mill in the market also produce only one size of corn grits per setting of the machine limiting the use of the machine. Also, most available designs are for the village and commercial-level production, making them out of a small farm operator's financial capability. Thus, this paper aims to design, fabricate, and evaluate a hammer mill for small-scale corn milling operation. Specifically, it aims to design and fabricate the machine base on locally available materials, evaluate the performance of the machine in terms of capacity and efficiency of milling, evaluate the performance of the machine in terms of separation of fine and coarse grits, and evaluate the financial viability of the small-scale milling machine. 


\section{LITERATURE REVIEW}

A large-scale hammer mill, as described by Koch (2002), has a rotor speed of approximately $1,800 \mathrm{rpm}$, should have about 10 inches $(254 \mathrm{~mm})$ long hammers. The width should be 2.5 inches $(63.5 \mathrm{~mm})$, and thickness should be 0.25 inches $(6.4$ $\mathrm{mm})$. Koch (2002) also added that rotor speed about 3,600 rpm should have 6 to 8 inches ( 150 to $200 \mathrm{~mm}$ ) long hammers. The width should be 2 inches $(50 \mathrm{~mm})$, and thickness should be 0.25 inches $(6.4 \mathrm{~mm})$. The arrangement of the hammers should be balanced and do not trail one another. The distance between hammer and screen, also described by Koch (2002), should be 0.5 inches ( 12 to $14 \mathrm{~mm}$ ) for size reduction of cereal grains.

El Shal et al.(2010) found in his design that the drum speed of $2,250 \mathrm{rpm}(33.56 \mathrm{~m} / \mathrm{s})$, grain moisture content $(10 \%)$, concave clearance $(5 \mathrm{~mm})$, and hammer thickness $(5 \mathrm{~mm})$ increases the percentage of fine milled corn and decreases coarse milled corn for pelleting feed. El Shal et al. (2010)also added in his study that drum speed of about 1,550 rpm $(23.12 \mathrm{~m} / \mathrm{s})$, grain moisture content $(14 \%)$, concave clearance $(12 \mathrm{~mm})$, and hammer thickness $(1.5 \mathrm{~mm})$ decreases the fine milled corn and increases coarse milled corn and medium milled corn.

The open area on the perforated screen of a hammer mill determines the particle size and milling efficiency. The recommended ratio of open area to the horsepower for grains, according to Bliss (1990) as cited by Koch (2002), would be 8 to 9 square inch $(55 \mathrm{~cm} 2)$ per horsepower. Lesser open area leads in the generation of heat, decreasing the capacity of the hammer mill.

Cyclone separator is a system also added to hammer mills to separate high-density particles from light particles. The suction fan on the system also places the milling chamber under negative pressure conveying the air with the ground feed out of the screen. This increases the throughput of the milling machine and reduces the heat retained inside the milling chamber (McKinney, 2008).

\section{METHODOLOGY}

\section{a) Design of the Hammer Mill Machine}

A small-scale hammer mill was designed, as shown in Figure 1. The designed hammer mill machine is comprised of the prime mover, the milling chamber, the inlet, the grits outlet, the suction fan, and the cyclone separator.

The machine was designed for small-scale corn milling operations to separate the fine milled corn from the coarse milled corn. Also, the machine was conceptualized to be simple in design to reduce investment cost, made out of locally available materials and components as possible for easy repair and maintenance of the machine, lightweight for easy transportation, and easy to repair and maintain by providing easy access to the major components of the machine.

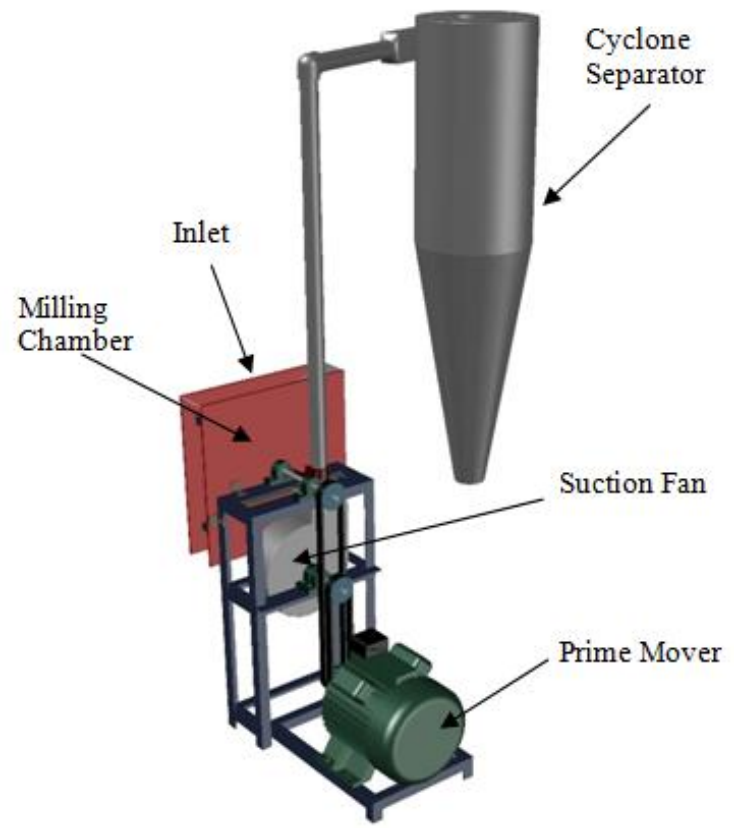

Figure 1: Design of the small-scale hammer mill machine

\section{b) Equipment and Materials}

The equipment used in the construction of the machine were arc welding, grinding tools, vise, clamp, electric drill, wrench, sheet cutter, measuring device, and hammer.

The materials used in the construction of the machine were $6.4 \mathrm{~mm}$ and $3.2 \mathrm{~mm}$ thick steel plate, $25.4 \mathrm{~mm} \times 3.2 \mathrm{~mm}$ angle bar, pulleys, $38.1 \mathrm{~mm}$ G.I. pipe and elbow, gauge 16 G.I. sheet, lift spring, $19.1 \mathrm{~mm}$ shafting, pillow block, $19.1 \mathrm{~mm}$ metal bushing, bolts, nuts and washers, and hose clamp.

\section{c) Principle of Operation}

The input product (corn) will be feed into the milling chamber through the inlet of the machine. When corn drops to the milling chamber, the rotating hammers driven by the electric motor via belt and pulley will strike the product continuously until the size is reduced to pass to the screen. The milled product will have a different size from fine corn grits to course corn grits. The coarse corn grits which have higher density will fall by gravity to the opening just below the milling chamber (grits outlet). The fine corn grits are sucked by the fan driven by the electric motor. These are conveyed to the cyclone separator that serves as the discharge chute of the fine corn grits. 
ISSN (online): 2581-3048

\section{d) Testing and Evaluation}

Corn was used as test materials during the preliminary testing and evaluation of the machine. Four different tip speed of the hammer was used during the evaluation. These tip speeds were based on four different available pulleys used on the hammer mill with respect to the rpm of the electric motor. The tip speeds are $28 \mathrm{~m} / \mathrm{s}$ (2" diameter pulley), $22 \mathrm{~m} / \mathrm{s}\left(2 \frac{1}{2}\right.$ " diameter pulley), $19 \mathrm{~m} / \mathrm{s}$ (3" diameter pulley), and $14 \mathrm{~m} / \mathrm{s}(4$ " diameter pulley). These treatments were evaluated with three (3) replications for each tip speed. Two kilograms of corn sample was used for every replication.

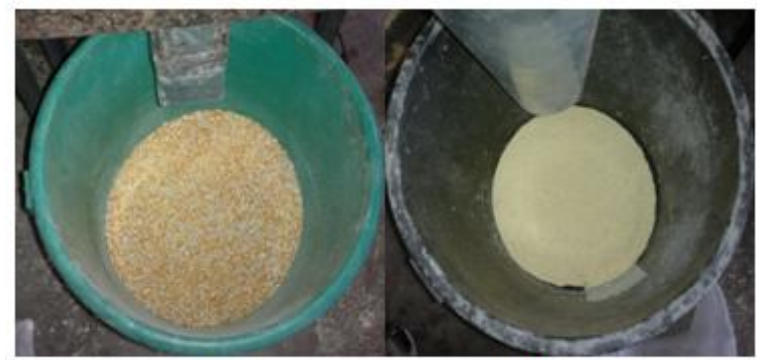

(a)

(b)

Figure 2: Collected sample at the (a) grits outlet and (b) cyclone separator

After milling the test materials, the output from the grits outlet and the cyclone separator was collected, as shown in Figure 2. They were subjected to a mechanical sieve individually to separate the different sizes of the grits (Figure $3)$. The sizes of the mechanical sieve used were $4,2,1,1 / 2$, and $1 / 4 \mathrm{~mm}$.

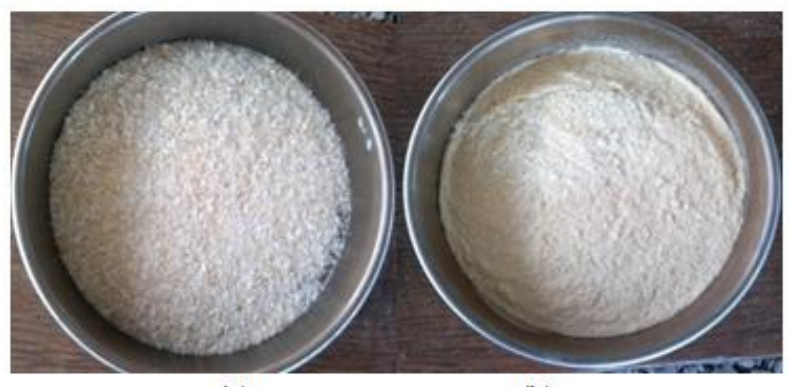

(a)

(b)

Figure 3: Sample retained at the (a) $2 \mathrm{~mm}$ sieve and (b) $1 \mathrm{~mm}$ sieve

The parameters used in evaluating the performance of the machine were the milling capacity, efficiency, particle size of the milled product, and electrical energy consumption. The formulas used were based on the Philippine Agricultural Engineering Standard 2017:2004. These were given in the following;

\section{Milling Capacity}

The milling capacity of the machine is the measure of the weight of corn milled per unit hour.

$$
\mathrm{C}_{\mathrm{m}}=\frac{\mathrm{W}_{\mathrm{m}}}{\mathrm{T}_{\mathrm{o}}}
$$

Where in,

$\mathrm{C}_{\mathrm{m}}=$ milling capacity, $\mathrm{kg} / \mathrm{hr}$

$\mathrm{W}_{\mathrm{m}}=$ weight of the milled corn, $\mathrm{kg}$

$\mathrm{T}_{\mathrm{O}}=$ total time of operation starting from the feeding of test material until the last drop of test material out of the machine, hr

\section{Milling Efficiency}

The milling efficiency is the measure of the size reduction capability of the machine in percentage. The weight of the milled corn that passed on the number $2 \mathrm{~mm}$ and number 4 $\mathrm{mm}$ size sieve is properly milled because of the number 16 mesh sieve used during the evaluation.

$$
\mathrm{E}_{\mathrm{m}}=\frac{\mathrm{W}_{\mathrm{r}}}{\mathrm{W}_{\mathrm{t}}} \times 100
$$

Where in,

$$
\begin{aligned}
& \mathrm{E}_{\mathrm{m}}=\text { milling efficiency, } \% \\
& \mathrm{~W}_{\mathrm{r}}=\text { weight of the milled corn that passed on the }
\end{aligned}
$$
number $2 \mathrm{~mm}$ and number $4 \mathrm{~mm}$ size sieve, $\mathrm{kg}$

$$
\mathrm{W}_{\mathrm{t}}=\text { total weight of the milled corn, } \mathrm{kg}
$$

\section{Particle Size of the Milled Product}

The particle size of the milled product is the measure of the size of milled corn grits in $\mathrm{mm}$.

$$
\begin{aligned}
& \mathrm{D}=0.0041\left(2^{\mathrm{FM}}\right) \\
& \mathrm{D}_{\mathrm{m}}=\mathrm{D} \times \frac{25.4 \mathrm{~mm}}{1 \mathrm{inch}}
\end{aligned}
$$

Where in,

$$
\begin{aligned}
& \mathrm{D}=\text { particle size }, \text { in } \\
& \mathrm{D}_{\mathrm{m}}=\text { particle size }, \mathrm{mm} \\
& \mathrm{FM}=\text { fineness modulus }
\end{aligned}
$$

\section{Electric Energy Consumption}

The electric energy consumption is the measure of the electrical consumption of the machine during operation in watt-hour.

$$
\mathrm{P}_{\mathrm{c}}=\mathrm{I} \times \mathrm{E} \times \mathrm{T}_{\mathrm{o}}
$$

Where in,

$\mathrm{P}_{\mathrm{c}}=$ electric energy consumption, $\mathrm{W}-\mathrm{hr}$
$\mathrm{I}=$ current consumed, $\mathrm{A}$
$\mathrm{E}=$ voltage rating of the electrical source, $\mathrm{V}$
$\mathrm{T}_{\mathrm{o}}=$ total time of operation starting from the feeding of test material until the last drop of test material out of the machine, $\mathrm{hr}$ 
ISSN (online): 2581-3048

\section{e) Statistical Analysis}

The statistical design used on the analysis of variance of the hammer tip speed $(28 \mathrm{~m} / \mathrm{s}, 22 \mathrm{~m} / \mathrm{s}, 19 \mathrm{~m} / \mathrm{s}$, and $14 \mathrm{~m} / \mathrm{s})$ was a completely randomized design (CRD) at a 5\% level of significance. Duncan's Multiple Range Test (DMRT) was used for the comparison of the means test.

\section{f) Simple Cost Analysis}

The parameters considered in the simple cost analysis of the machine were the break-even point, net income, payback period, and benefit-cost ratio.

\section{RESULTS AND DISCUSSIONS}

\section{a) General Description of the Machine}

The designed and fabricated hammer mill, shown in Figure 4 , comprises of the prime mover, the milling chamber, the inlet, the grits outlet, the screen, the suction fan, and the cyclone separator.

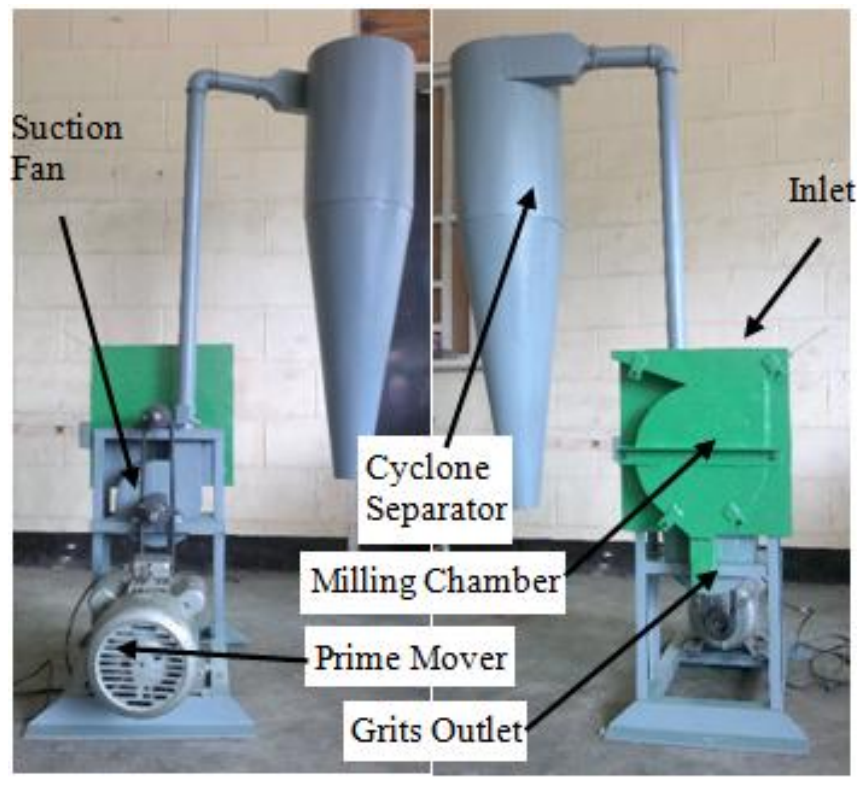

Figure 4: Fabricated small-scale hammer mill machine

The prime mover is a three horsepower electric motor with a speed of 1,740 rpm. The milling chamber of the machine is comprised of ten (10) swinging hammers, which have a thickness of $3.1 \mathrm{~mm}$, a width of $25.4 \mathrm{~mm}$, and a length of 76.2 $\mathrm{mm}$. These hammers were spaced evenly using nuts so that they will not trail each other. The hammer plates have a thickness of $6.4 \mathrm{~mm}$ and a diameter of $203.2 \mathrm{~mm}$. The hammer plate was drilled with four equally distributed $9.5 \mathrm{~mm}$ diameter hole at a distance of $50.8 \mathrm{~mm}$ from the center for the bolts that will hold the hammers will be inserted. A $3.1 \mathrm{~mm} \mathrm{x}$ $76.2 \mathrm{~mm}$ flat bar was used as an inlet and a casing on both sides of the machine. The screen is a $6.4 \mathrm{~mm}$ perforated screen covered with number 16 mesh sieve. The fan used in the design was an axial-flow fan with five blades. The cyclone separator has a diameter of $279.4 \mathrm{~mm}$ and a height of 1117.6 $\mathrm{mm}$. This is connected to the fan using a $914.4 \mathrm{~mm}$ long and $38.1 \mathrm{~mm}$ diameter G.I. pipe. The fan, the fan casing, and cyclone separator were made of gauge 16 G.I. sheet.

\section{b) Performance Evaluation of the Machine}

The analysis of the performance of the machine was based on the result of the different parameters that include the milling capacity, milling efficiency, particle size of the milled product, and electrical energy consumption. The summary of the result for the capacity and power consumption are presented in Table 1.

Table 1: Summary of the result of the machine performance in terms of capacity and power consumption

\begin{tabular}{|c|c|c|}
\hline Tip Speed (m/s) & $\begin{array}{c}\text { Capacity } \\
\text { (kg/hr) }\end{array}$ & $\begin{array}{c}\text { Electrical Energy } \\
\text { Consumption } \\
\text { (W-hr) }\end{array}$ \\
\hline 28 & $88.21^{\mathrm{a}}$ & $33^{\mathrm{a}}$ \\
\hline 22 & $44.91^{\mathrm{b}}$ & $66^{\mathrm{b}}$ \\
\hline 19 & $33.58^{\mathrm{b}}$ & $84^{\mathrm{b}}$ \\
\hline 14 & $32.06^{\mathrm{b}}$ & $85^{\mathrm{b}}$ \\
\hline $\begin{array}{l}\text { Note: Values with the same letter do not statistically vary } \\
\text { significantly at 5\% level of significance. }\end{array}$ \\
\hline
\end{tabular}

Based on Table 1, the result of the milling capacity shows that as the tip speed increases, the capacity of the machine increases. This implies that the machine is recommended to be operated at $28 \mathrm{~m} / \mathrm{s}$ tip speed to obtain a high milling capacity of $88.21 \mathrm{~kg} / \mathrm{hr}$. On the result of the electrical energy consumption of the machine, the electrical energy consumption decreases as the tip speed increases. This is due to the longer time it takes to mill the corn at lower tip speed consuming higher electrical energy.

Table 2 presents the summary of the efficiency and the particle size of the output of the machine from the coarse grit outlet and the cyclone separator.

Table 2: Summary of the result of the machine performance in terms of particle size and milling efficiency

\begin{tabular}{|c|c|c|c|}
\hline \multirow{2}{*}{$\begin{array}{c}\text { Tip Speed } \\
(\mathbf{m} / \mathbf{s})\end{array}$} & $\begin{array}{c}\text { Efficiency } \\
(\boldsymbol{\%})\end{array}$ & $\begin{array}{c}\text { Particle Size (mm) } \\
\text { Coarse Grit } \\
\text { Outlet }\end{array}$ & $\begin{array}{c}\text { Cyclone } \\
\text { Separator }\end{array}$ \\
\hline 28 & $92.42^{\mathrm{a}}$ & $0.85^{\mathrm{a}}$ & $0.41^{\mathrm{a}}$ \\
\hline 22 & $85.62^{\mathrm{b}}$ & $1.25^{\mathrm{bc}}$ & $0.45^{\mathrm{a}}$ \\
\hline 19 & $85.77^{\mathrm{b}}$ & $1.11^{\mathrm{b}}$ & $0.43^{\mathrm{a}}$ \\
\hline 14 & $80.18^{\mathrm{b}}$ & $1.39^{\mathrm{c}}$ & $0.46^{\mathrm{a}}$ \\
\hline $\begin{array}{l}\text { Note: Values with the same letter do not statistically vary } \\
\text { significantly at 5\% level of significance. }\end{array}$ \\
\hline
\end{tabular}


ISSN (online): 2581-3048

The result of the milling efficiency shows that the highest tip speed has the highest efficiency of $92.42 \%$. This due to the high collision impact of the hammer and the corn. If the hammer has high tip speed, the time for the size reduction before passing through the screen is shorter compared to lower tip speed. On the analysis of particle size, the average particle size of the milled corn collected at the cyclone separator was below the $1.17 \mathrm{~mm}$ size of the screen, with $28 \mathrm{~m} / \mathrm{s}$ having the smallest particle size of $0.41 \mathrm{~mm}$. This particle size is classified as "fine" by Henderson and Perry (1976) for shelled corn based on its fineness modulus. On the other hand, milled corn collected at the coarse grits outlet had an average size of below $1.17 \mathrm{~mm}$ for the tip speed of $28 \mathrm{~m} / \mathrm{s}$ and $19 \mathrm{~m} / \mathrm{s}$ with $0.85 \mathrm{~mm}$ and $1.11 \mathrm{~mm}$, respectively. These sizes are classified as "medium" by Henderson and Perry (1976) for shelled corn based on its fineness modulus. Corn grits collected from the tip speed of $22 \mathrm{~m} / \mathrm{s}$ and $14 \mathrm{~m} / \mathrm{s}$ are classified as "coarse" based on their fineness modulus (Henderson and Perry, 1976).

The utilization of the machine with a custom rate of 2 $\mathrm{Php} / \mathrm{kg}$ and revealed that the machine is economically viable to the farmer. The summary of the result of the simple cost analysis of the machine is shown in Table 3.

Table 3: Summary of the result of the simple cost analysis of the machine

\begin{tabular}{|c|c|c|}
\hline Parameters & $28 \mathrm{~m} / \mathrm{s}$ & $22 \mathrm{~m} / \mathrm{s}$ \\
\hline Break-Even Point, kg/yr & 4433.95 & 6642.94 \\
\hline Net Income, Php/yr & $182,301.78$ & $57,597.78$ \\
\hline Payback Period, months & 1.65 & 5.21 \\
\hline Benefit-Cost Ratio & 20.56 & 4.34 \\
\hline
\end{tabular}

\section{CONCLUSION}

A hammer mill for small-scale corn milling operation was designed and fabricated following the design considerations, which are simple in design to reduce investment cost, made out of locally available materials and components, lightweight for easy transportation, and easy to repair and maintain. Evaluation of the machine performance shows that the hammer mill can be operated depending on the farmer's need for the size of the corn grits. "Fine" corn grits can be collected at the cyclone separator at different tip speed. When the need is "medium" corn grits, the hammer mill is recommended to be operated at $28 \mathrm{~m} / \mathrm{s}$. This tip speed has a milling capacity of $88.21 \mathrm{~kg} / \mathrm{hr}$, milling efficiency of $92.42 \%$, and electrical power consumption of $33 \mathrm{~W}$-hr. For "coarse" corn grits, the hammer mill is recommended to be operated at $22 \mathrm{~m} / \mathrm{s}$ tip speed. This tip speed has a higher capacity and lower electrical energy of $44.91 \mathrm{~kg} / \mathrm{hr}$ and $66 \mathrm{~W}$-hr, respectively, compared to $19 \mathrm{~m} / \mathrm{s}$ and $14 \mathrm{~m} / \mathrm{s}$.

\section{REFERENCES}

[1] El Shal, M.S., Tawfik, M.A., El Shal, A.M. and Metwally, K., "A Study the Effect of Some Operational Factors on Hammer Mill”, Misr J. Ag. Eng., 27(1): 5474, January 2010.

[2] Henderson, S.M. and Perry, R.L., "Agricultural Process Engineering", $3{ }^{\text {rd }}$ Ed., Westport, Connecticut, 1976.

[3] Koch, Kim, "Hammer mills and Roller Mills", Northern Crops Institute, North Dakota State University, Fargo, North Dakota, 2002.

[4] Lyddon, Chris, "Focus on the Philippines", 2011.

[5] Mckinney, Leland and KS lelandm, "GRAIN PROCESSING: PARTICLE SIZE REDUCTION METHODS." (2008).

[6] Mississippi State University Extension, "Is particle size important for swine diets?", 2010.

[7] Philippine Agricultural Engineering Standard (PAES 217: 2004), Agricultural Machinery - Hammer Mill Methods of Test.

\section{Citation of this Article:}

Erickson N. Dominguez, "Design, Fabrication, and Performance Evaluation of a Hammer Mill for Small-Scale Corn Milling Operation" Published in International Research Journal of Innovations in Engineering and Technology - IRJIET, Volume 5, Issue 9, pp 46-50, September 2021. Article DOI https://doi.org/10.47001/IRJIET/2021.509007 